\title{
MANAGEMENT OF PARAURETHRAL CYSTS IN ADULT WOMEN: EMPHASIS ON PHYSICAL EXAMINATION (A SHORT SERIES)
}

\author{
Dalal H Alshammaa ${ }^{1}$, Hanan Al-Salem ${ }^{1}$, Mariam M. Al-Mansouri' ${ }^{1}$, \\ Abdullatif E. Al-Terki², and Tariq F. Al-Shaiji2* \\ ${ }^{1}$ Department of Obstetrics and Gynecology, Maternity Hospital, Kuwait City, Kuwait \\ ${ }^{2}$ Urology Unit, Department of Surgery, Amiri Hospital, Kuwait City, Kuwait \\ *Corresponding Author E-mail: tshaiji@gmail.com; Tel: +965 99773789
}

Cite this article:

Dalal H A., Hanan A., Mariam M.A., Abdullatif E.A., Tariq F. A. (2021), Management of Paraurethral Cysts in Adult Women: Emphasis on Physical Examination (A Short Series). African Journal of Health, Nursing and Midwifery 4(2), 67-75. DOI: 10.52589/AJHNMYJDCFQHY.

\section{Manuscript History \\ Received: 4 April 2021 \\ Accepted: 29 April 2021 \\ Published: 7 May 2021}

Copyright $\odot 2020$ The Author(s). This is an Open Access article distributed under the terms of Creative Commons AttributionNonCommercial-NoDerivatives 4.0 International (CC BY-NC-ND 4.0 ), which permits anyone to share, use, reproduce and redistribute in any medium, provided the original author and source are credited.
ABSTRACT: Introduction: Paraurethral cysts in adult women are rare. These masses present with non-specific symptoms, making them indistinguishable clinically. The assessment of urethral anatomy is largely based on imaging studies. This study aims to present clinical experience in managing paraurethral cysts. Methods: We present a retrospective chart review of a series of four patients diagnosed with paraurethral cysts that presented to our practice between December 2015 and April 2017, as well as a review of the literature describing these lesions. Paraurethral swellings were initially diagnosed on vaginal examination and further investigated by MRI. The reported cases included patients that underwent surgical excision and those that declined surgery. Results: Our studied cohort included both nulliparous and multiparous patients. The chief presenting complaints were pelvic area pain and tender anterior vaginal swelling. Most patients reported a history of previous intermittent swelling and its resolution. In patients that underwent surgical intervention, all responded well to excision of the cyst with no recurrence. Discussion: Acquired paraurethral cysts are often attributed to prior vaginal delivery or surgical trauma. However, we report a nulliparous patient with no prior vaginal procedure. Physical examination of symptomatic patients was essential in diagnosis and management. Conservative treatment in the patients declining surgery was unsuccessful and the cyst persisted. Conclusions: A review of patients' history and vaginal examination was sufficient in detecting paraurethral cysts. In cases where a cyst was not detectable and the patient reported recurrent swelling, reexamination, when the patient became symptomatic, was successful in diagnosing the swelling. However, MRI investigation was necessary to review the extent of the lesions prior to complete surgical excision. Excision was effective in all the patients, with no recurrence.

KEYWORDS: Paraurethral Cyst, Anterior Vaginal Wall Swelling, Physical Examination 


\section{INTRODUCTION}

Acquired paraurethral cysts are rare pathologies with a reported incidence of 1-6\% [1-2]. However, their true incidence is unknown due to limitations in the available literature that mainly comprises small case series and the frequently asymptomatic nature of these cysts, resulting in their underdiagnosis. $2.9 \%$ of asymptomatic women have paraurethral swellings [1-2].

Clinical awareness and advances in imaging modalities have contributed to their increasing incidence. These cysts are usually diagnosed in the third to fifth decades of life [3-4]. The differential is broad encompassing urethral caruncles, Skene's gland cysts, ectopic ureterocele, urethral prolapse, urethral diverticula, cysts of embryonic origins (Gartner's and Müllerian ducts), leiomyoma and rarely malignant lesions [1]. Of these diagnoses, urethral diverticulum (UD) is the most common etiology of paraurethral masses, accounting for $84 \%$ of paraurethral swellings [5]. UD is acquired as a result of recurrent inflammation of the paraurethral glands with abscess formation.

This leads to cystic dilatation, and the rupture in the lumen of the urethra. Leiomyoma and vaginal wall cysts comprise the second and third most common causes respectively [4-5]. Inclusion cysts are believed to be the most common vaginal wall cysts. They result from trauma by instrumentation or childbirth and are often small and asymptomatic. Presenting symptoms are variable and nonspecific, mimicking other urological conditions and posing a diagnostic challenge. These symptoms include recurrent urinary tract infections (UTI), urinary frequency/urgency, post-void dribbling, vaginal mass and dyspareunia. The wide array of clinical presentations and anatomical configurations make these cysts indistinguishable clinically [1].

\section{METHODS}

Informed consent was obtained from all patients as part of involved hospital guidelines as well as hospital approval, to carry out this study. We retrospectively reviewed our experience with the diagnosis and management of four patients found to have paraurethral cystic lesions between December 2015 and April 2017, who had either received surgical excision or declined any intervention. Of the patients, two had self-presented to the urogynecological service complaining of recurrent episodes of a painful anterior vaginal swelling with discharge and one patient had been referred by her gynecologist after reporting the same complaint (figure 1). One patient had been receiving treatment for recurrent culture-positive UTIs for several years when a physical examination revealed an anterior paraurethral lesion. A full history, physical examination, urinalysis, urethrocystoscopy and pelvic MRI were performed in all patients (figures $2 \& 3$ ).

In the patient complaining of recurrent UTIs, a urodynamic assessment was also performed. Transvaginal excision of the cyst was performed in three patients while one patient declined surgical intervention (figures 4 \& 5). A 14-French Foley catheter was inserted intraoperatively and kept for a week prior to its removal. All patients received a daily low dose of Anticholinergic agent following the procedure and a one-week course of oral antibiotics. Patients were seen one week after surgery for Foley catheter removal. They were then seen again two weeks following removal for review of any voiding symptoms. 
African Journal of Health, Nursing and Midwifery

ISSN: 2689-9418

Volume 4, Issue 2, 2021 (pp. 67-75)

www.abjournals.org

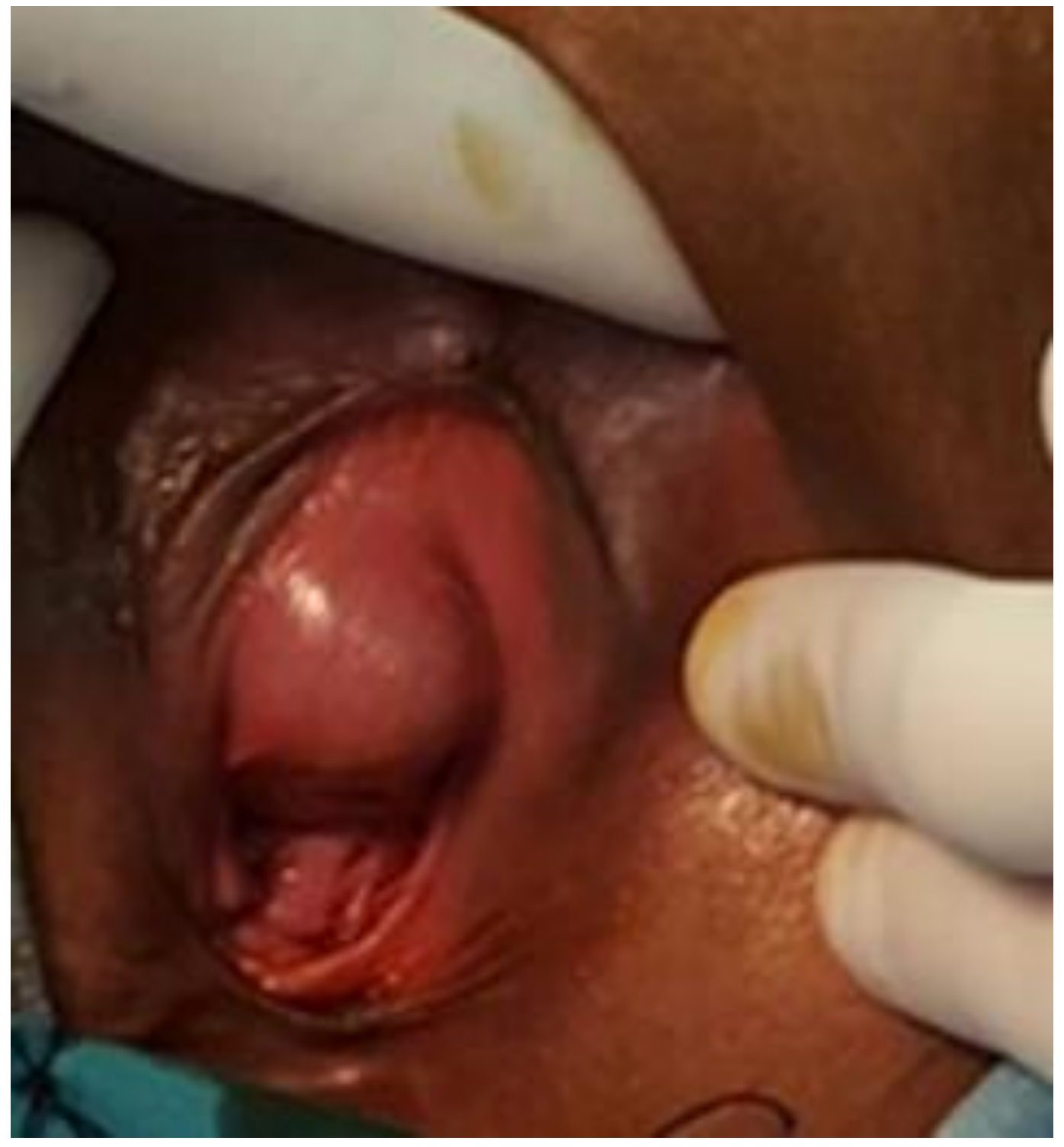

Figure 1. Anterior Vaginal Wall Swelling Inferior to the Urethral Opening. 
African Journal of Health, Nursing and Midwifery

ISSN: 2689-9418

Volume 4, Issue 2, 2021 (pp. 67-75)

www.abjournals.org
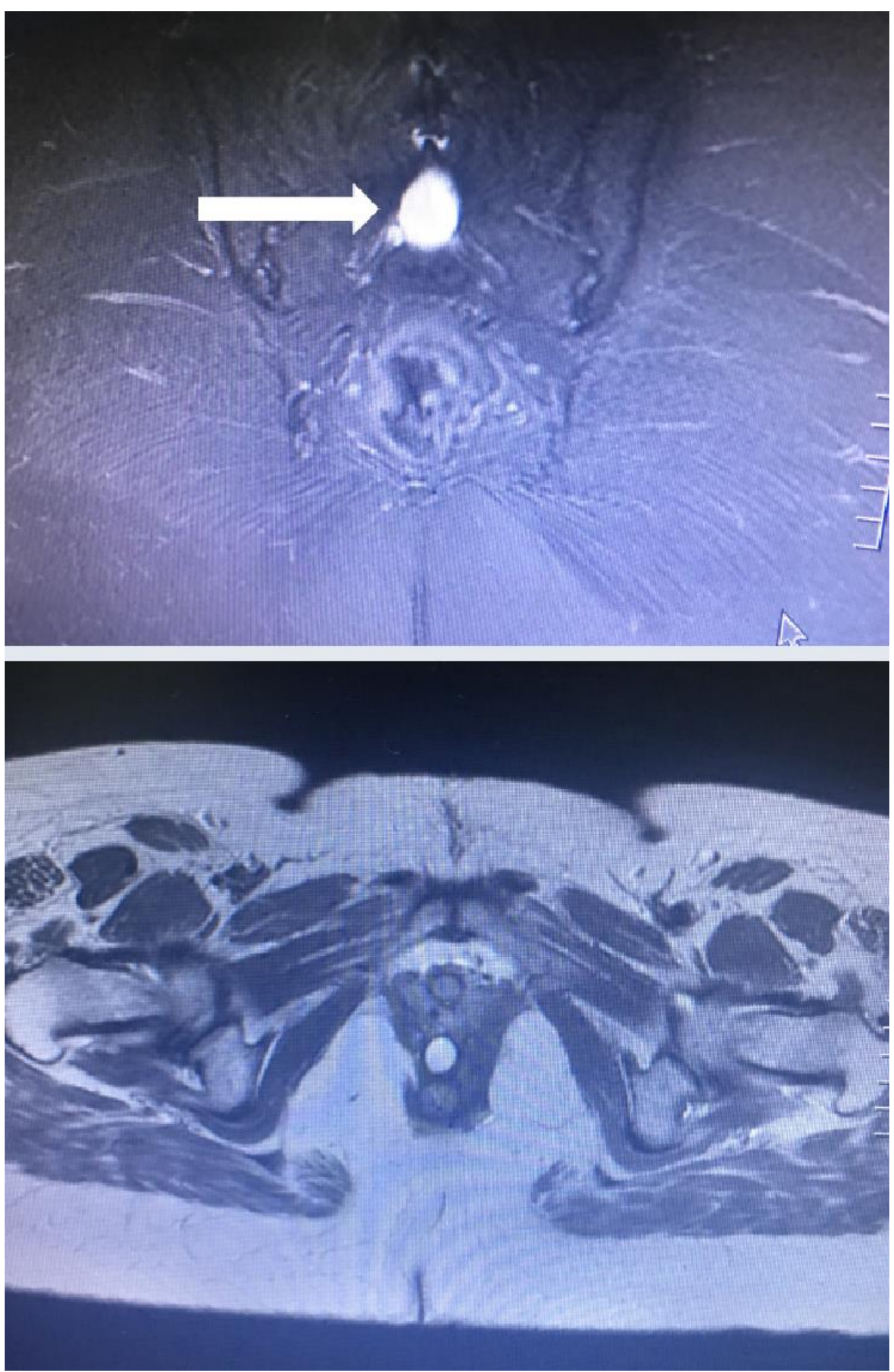

Figures 2 and 3. T2 weighted MRI image revealing a thin-walled cystic lesion measuring $12 \times 14 \times 22 \mathrm{~mm}$ located below the level of the pubic symphysis and in the lower third of the vagina with no communication with surrounding structures. 
African Journal of Health, Nursing and Midwifery

ISSN: 2689-9418

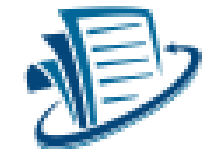

Volume 4, Issue 2, 2021 (pp. 67-75)

www.abjournals.org

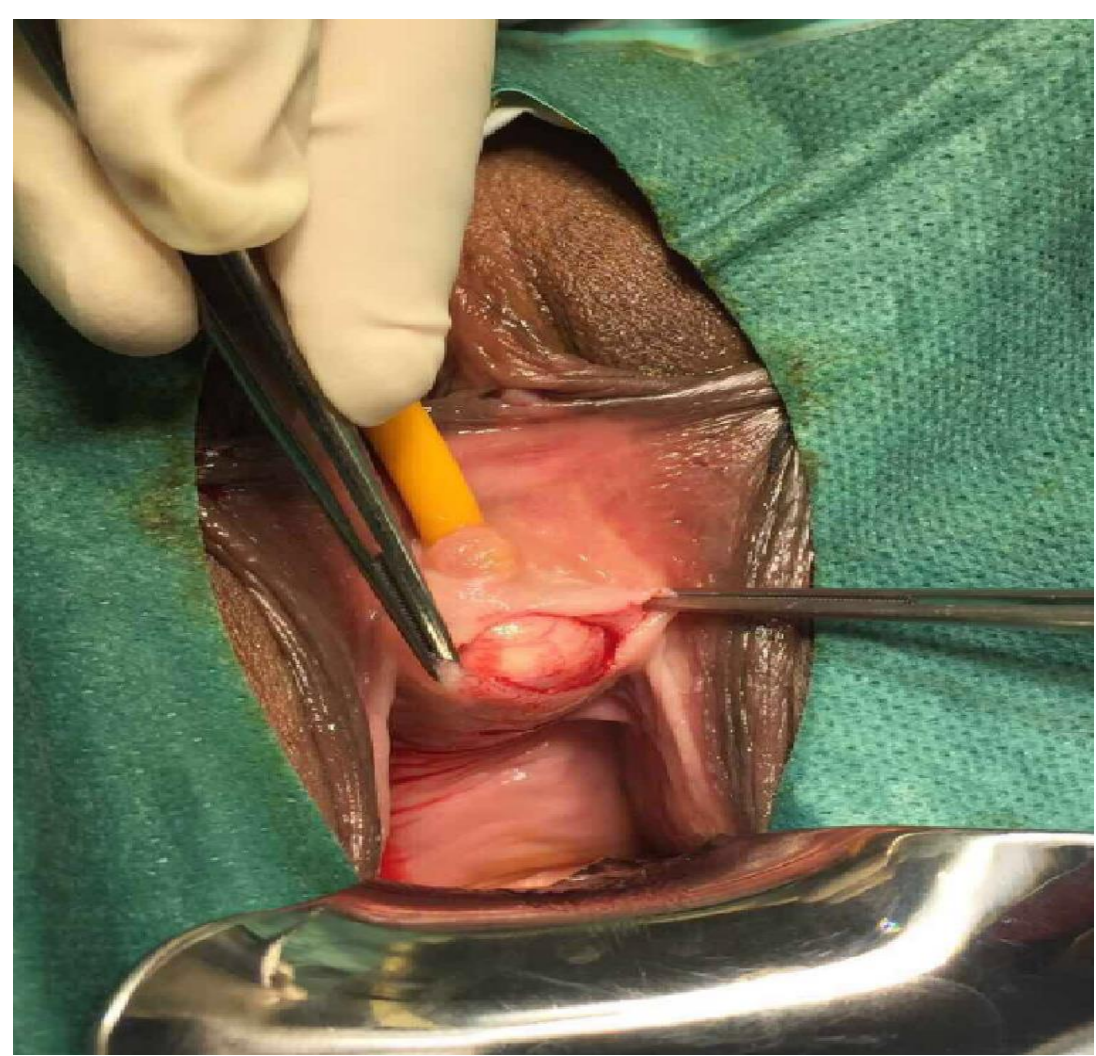

Figure 4. Cyst located inferior to the urethral meatus.

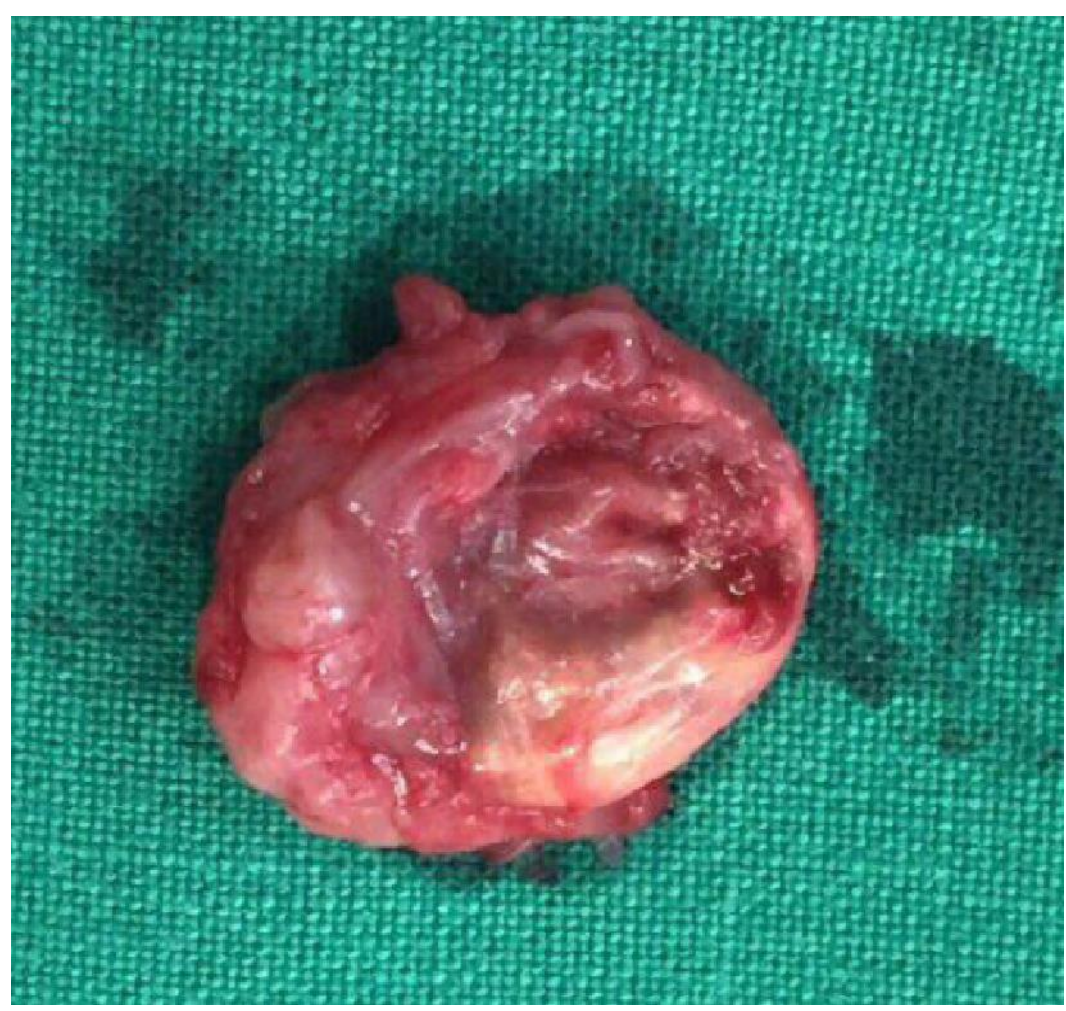

Figure 5. Excised Paraurethral Cyst 


\section{RESULTS}

Four patients were investigated for paraurethral cystic lesions. The mean age was 39.5 years; range 26-49 years (table 1). The most commonly reported complaints were painful anterior vaginal swelling and pelvic pain or discomfort (table 2). Two patients reported similar previous episodes with spontaneous rupture of the cyst and resolution of pain. The number of previous episodes ranged from 2 to 4 . None of the patients had undergone any surgical intervention for this complaint. In one patient, no mass was identified at the initial presentation.

Re-examination performed when she had become symptomatic again successfully identified the mass. Three patients underwent surgical excision of the cyst with the most common histopathological findings being chronic inflammation (table 3). All the patients were discharged at 48 hours post-operation with a Foley catheter each, which was removed oneweek post-surgery. All the patients recovered well and none reported any de novo urinary symptoms. There was no recurrence at a mean follow-up of 9.444 months (range 4.25-20). The patient complaining of stress urinary incontinence prior to surgery reported resolution of the incontinence.

Table 1. Demographics; CS: cesarean section, NVD: normal vaginal delivery

\begin{tabular}{|c|c|c|c|c|}
\hline Case & Age at presentation & Parity & Location of cyst & Size \\
\hline 1 & 26 & Nulliparous & $\begin{array}{l}\text { Right superolateral to } \\
\text { the urethral meatus }\end{array}$ & $2.5 \mathrm{~cm}$ \\
\hline 2 & 36 & $\begin{array}{l}\text { Multiparous } \\
2 \text { NVD }\end{array}$ & $\begin{array}{l}\text { Right superolateral to } \\
\text { the urethral meatus }\end{array}$ & $1.8 \mathrm{~cm}$ \\
\hline 3 & 47 & $\begin{array}{c}\text { Multiparous } \\
1 \mathrm{CS} \\
2 \mathrm{NVD}\end{array}$ & $\begin{array}{l}\text { Superior to the urethral } \\
\text { meatus }\end{array}$ & $2 \mathrm{~cm}$ \\
\hline 4 & 49 & $\begin{array}{l}\text { Multiparous } \\
1 \text { CS } \\
2 \text { NVD }\end{array}$ & $\begin{array}{l}\text { Left inferolateral to the } \\
\text { urethral meatus }\end{array}$ & $2.2 \mathrm{~cm}$ \\
\hline
\end{tabular}


African Journal of Health, Nursing and Midwifery

ISSN: 2689-9418

Volume 4, Issue 2, 2021 (pp. 67-75)

Table 2. Preoperative symptoms

\begin{tabular}{|c|c|}
\hline $\begin{array}{c}\text { Tender anterior vaginal } \\
\text { swelling }\end{array}$ & No. Pts (\%) \\
\hline $\begin{array}{c}\text { Previous episodes of } \\
\text { vaginal swelling }\end{array}$ & $3(75 \%)$ \\
\hline Recurrent UTI & $2(50 \%)$ \\
\hline Pyrexia & $2(50 \%)$ \\
\hline Dysuria & $2(50 \%)$ \\
\hline Dyspareunia & $2(50 \%)$ \\
\hline Pelvic Pain & $1(25 \%)$ \\
\hline Urgency & $3(75 \%)$ \\
\hline Incontinence & $1(25 \%)$ \\
\hline Urinary retention & $1(25 \%)$ \\
\hline Hematuria & $0(0 \%)$ \\
\hline
\end{tabular}

Table 3. Histopathological findings

\begin{tabular}{|c|c|}
\hline $\begin{array}{c}\text { Lined by squamous } \\
\text { epithelium }\end{array}$ & No. Pts \\
\hline Ulceration & 2 \\
\hline Acute inflammation & 1 \\
\hline Chronic inflammation & 1 \\
\hline Fibrotic tissue & 3 \\
\hline
\end{tabular}




\section{DISCUSSION}

Studies report that the most common symptoms are pelvic pain and dyspareunia, followed by incontinence. Only $9 \%$ present with a chief complaint of an anterior vaginal mass [5]. In our cohort of patients, the most common presenting symptom is the sensation of painful vaginal swelling. There is no consensus on a diagnostic and therapeutic protocol of acquired paraurethral cysts in adult female patients. Treatment options include needle aspiration, awaiting spontaneous rupture, marsupialization and complete excision of the cyst. Reported success rate of simple marsupialization is about $97.6 \%$ with a mean follow-up of 5.5 years [4].

Complete excision of the cyst requires close dissection to the urethra and poses the risk of urethral injury with urinary incontinence, urethra-vaginal fistula formation and urethral stricture. Complete excision is recommended as these lesions are the result of chronic inflammation and although the majority of cases were of benign nature, $6 \%$ of urethral diverticula display histological evidence of malignancy [1]. CT or MRI performed preoperatively often fails to identify carcinoma in these cases. Multiple authors suggested that physical examination was sufficient in making the diagnosis and no further radiological investigations were necessary as they produced no impact on the treatment plan [3-5].

They recommended reservation of these investigations for more complicated cysts. However, on physical examination, only $53.8 \%$ of the masses are detected. The remainder is only evident on micturating cystourethrography (MCUG) (41\%) and during vaginal surgery (5\%) [5]. Imaging traditionally involves MCUG, double-balloon urethrography (DBU) and MRI with intravenous contrast, which has become the current imaging modality of choice due to its noninvasive nature. MRI can also demonstrate intra diverticular stones and malignancy, and can diagnose urethral diverticula with a sensitivity of 70-100\% [6-7]. There is a lack of consensus on which radiographic modality has the highest detection rate of paraurethral cysts. However, MRI, CT, MCUG and DBU all have sufficiently high detection rates [5].

\section{CONCLUSION}

Our experience suggests that physical examination is sufficient for preoperative diagnosis. However, we also believe that MRI has a role in distinguishing between the differential diagnoses, rule out urethral diverticulum complications and malignancy, and provide more information regarding the location of the lesion.

We recommend complete surgical excision-which is best performed when the patient is symptomatic - to minimize the risk of recurrence. Postponing surgery to when the patient became symptomatic was the optimum time to excise the cyst as it made dissection of the clearly demarcated swollen cyst easier and reduced the risk of urethral injury. 


\section{REFERENCES}

[1] Fletcher SG, Lemack GE. Benign masses of the female periurethral tissues and anterior vaginal wall. Curr Urol Rep. 2008 Sep;9(5):389-96.

[2] Ahmed K, Dasgupta R, Vats A, Nagpal K, Ashrafian H, Kaj B, et al. Urethral diverticula carcinoma: an overview of current trends in diagnosis and management. Int Urol Nephrol. 2010;42:331-41.

[3] Sharifiaghdas F, Ghaderian N. Female paraurethral cysts: experience of 25 cases. BJU Int. 2004;93:353-356.

[4] Sharifaghdas F, Daneshpajooh A, Mirzaei M. Paraurethral cysts in adult women: Experience with 86 cases. Urol J. 2014 Nov 1;11(5):1896-9.

[5] Blaivas JG, Flisser AJ, Bleustein CB, Panagopoulos G. Periurethral masses: Etiology and diagnosis in a large series of women. Obstet Gynecol. 2004 May; 103(5 Pt 1):8427.

[6] Portnoy O, Kitrey N, Eshed I, Apter S, Amitai MM, Golomb J. Correlation between MRI and double-balloon urethrography findings in the diagnosis of female periurethral lesions. Eur J Radiol. 2013 Dec; 82(12):2183-8.

[7] Bennet GL, Hecht EM, Tanpitukpongse TP, Babb JS, Taouli B, Wong S, et al. MRI of the urethra in women with lower urinary tract symptoms: Spectrum of findings at static and dynamic imaging. AJR. 2009 Dec;193:1708-1715. 